\title{
Comparative studies on the therapeutic and adverse effects of mirtazapine and fluoxetine in the treatment of adult depression
}

\author{
Liping Zhang ${ }^{1}$, Mei Long ${ }^{2}$, Lijuan $\mathrm{Xu}^{3}$ \\ ${ }^{1}$ The Medical Department of Zaozhuang Municipal Hospital, ${ }^{2}$ Department of Gynecology and Obstetrics, Zaozhuang Downtown \\ District Women and Children Health Care Hospital, ${ }^{3}$ Department of Science and Education, Zaozhuang Municipal Hospital, \\ Zaozhuang City, China
}

*For correspondence: Email: jv1174@163.com

Sent for review: 9 October 2018

Revised accepted: 27 December 2018

\begin{abstract}
Purpose: To evaluate comparatively the therapeutic and adverse effects of mirtazapine and fluoxetine for the management of adult depression.

Methods: Adults (58) with depression admitted to the Neurology Department of Zaozhuang Municipal Hospital from August 2014 to July 2016 were randomly assigned to either mirtazapine group or fluoxetine group. Those in mirtazapine group were given mirtazapine while the fluoxetine group took fluoxetine. The patients were graded for Hamilton Depression Scale (HAMD) and Treatment Emergent Symptoms Scale (TESS) scores before treatment and at weeks 2, 4, 6, and 8 post-treatment, with the aim of comparing therapeutic effects and adverse reactions to mirtazapine and fluoxetine.

Results: The therapeutic effects seen in the two groups did not differ significantly $(p>0.05)$, but mirtazapine had a slight advantage over fluoxetine. Effectiveness appeared after 2 weeks in the mirtazapine group, and 4 weeks in the other group. Moreover, there were significant differences in HAMD scores between the two groups after 2 and 4 weeks of treatment $(p<0.05)$, but the differences in scores after 6 and 8 weeks of treatment were not significant $(p>0.05)$. However, there were significant differences in score between pretreatment and 8-week post-treatment scores $(p<0.05)$. Mirtazapine group also had lower incidents of adverse reactions (sleepiness, dyspepsia, nausea, vomiting, excitation, and headache) than the fluoxetine group $(p<0.05)$.

Conclusion: Mirtazapine has similar effect as fluoxetine in the treatment of adult depression, but works faster, with low incidence of adverse reactions. Thus, it is a safer and quicker antidepressant for clinical application.
\end{abstract}

Keywords: Mirtazapine, Fluoxetine, Adult depression, Clinical effect, Adverse reactions

\begin{abstract}
This is an Open Access article that uses a funding model which does not charge readers or their institutions for access and distributed under the terms of the Creative Commons Attribution License (http://creativecommons.org/licenses/by/4.0) and the Budapest Open Access Initiative (http://www.budapestopenaccessinitiative.org/read), which permit unrestricted use, distribution, and reproduction in any medium, provided the original work is properly credited.

Tropical Journal of Pharmaceutical Research is indexed by Science Citation Index (SciSearch), Scopus, International Pharmaceutical Abstract, Chemical Abstracts, Embase, Index Copernicus, EBSCO, African Index Medicus, JournalSeek, Journal Citation Reports/Science Edition, Directory of Open Access Journals (DOAJ), African Journal Online, Bioline International, Open-J-Gate and Pharmacy Abstracts
\end{abstract}

\section{INTRODUCTION}

Depression is a mood disorder characterized by low mood, excess inferiority, decreased activity, suicidal tendencies, and other violent behaviors [1]. About 1.2 million people die from depression every year worldwide, making it a very harmful disease with high incidence and mortality in 
adults, with heavy financial burden on families and society [2]. In recent years, some studies have shown that diabetes, hypertension, and depression are three sources of danger to human health [3]. It has been projected that depression will rank amongst the ten major diseases in the world by 2020 [4]. Therefore, it is necessary to find safe and effective therapies for this disease. Nowadays, electroshock therapy, cognitive therapy, and medication are major therapies, among which medication is the most popular. Mirtazapine and fluoxetine are most commonly used medical treatments for depression in clinical settings. The present study was aimed at investigation of differences in the clinical effects and adverse reactions associated with mirtazapine and fluoxetine in the treatment of adult depression. This was with a view to providing a reference for clinical treatment of the disease.

\section{METHODS}

\section{Patients' profile and ethical approval}

A total of 158 adults with depression admitted in the Neurology Department of Zaozhuang Municipal Hospital from August 2014 to July 2016, who conformed to the depression diagnosis criteria in Chinese Classification and Diagnosis of Mental Diseases, were enrolled in the study [5]. The included patients were those aged 18 - 55 years, patients who scored more than 18 in HAMD, and patients who signed informed consent. In addition, patients whose blood showed no apparent abnormality with respect to complete blood count (CBC), and those with normal ECG were included in the study.

On the other hand, patients with severe organ diseases and organic disorders, patients with history of alcohol and drug dependence, pregnant and lactating women, and patients with suicidal tendencies, were excluded. The patients were randomly assigned to either mirtazapine group or fluoxetine group (79 in each group). There were 34 males and 45 females in the mirtazapine group, aged 18 - 55 years (mean age $=34.6 \pm 2.9$ years), with disease duration of 1 - 14 months (mean course $=9.5 \pm 1.7$ months). There were 39 males and 40 females in the fluoxetine group, aged 19 - 55 years (mean age $=35.9 \pm 3.2$ years), with disease course in the range of 1.5 - 15.5 months (mean course $=10.3$ \pm 0.7 months). There were no apparent differences in age, sex and disease duration of patients between the two groups $(p>0.05)$. The research was approved by the Ethical Committee of Department of Science and Education,
Zaozhuang Downtown District Women and Children Health Care Hospital, Shandong Province, China (approval no. 201810105), and was performed as per the guidelines of Helsinki Declaration of 1964 as amended in 1996 [6].

\section{Treatment}

The patients did not take any antipsychotic and antidepressant drugs 10 days before treatment. The 79 patients in the mirtazapine group were given mirtazapine (20 mg/day starting dose), and if patients did not get better after 2 to 3 days of treatment, the dose was raised to $35 \mathrm{mg} /$ day ( maximum of $45 \mathrm{mg} /$ day, mean $=30.46 \mathrm{mg} /$ day). The other group was treated with fluoxetine at a starting dose of $18 \mathrm{mg} /$ day, which was raised to $30 \mathrm{mg} /$ day if the patients did not improve after 2 to 3 days (maximum of $40 \mathrm{mg} /$ day, mean $=30.78$ $\mathrm{mg} /$ day). All medicines were administered daily in the morning for two weeks. The clinical effects after four treatment courses were recorded. During treatment, patients in both groups did not take any other antipsychotic drugs or mood stabilizers.

\section{Assessment of treatment effectiveness}

The two groups were graded for HAMD scores before treatment, and at weeks 2, 4, 6, and 8 after treatment. Effectiveness was classified into four ranks according to the degree of reduction in HAMD score: $\geq 75 \%$ reduction was classified as healed; 50 to $75 \%$ reduction was evidently effective; 25 to $50 \%$ reduction was effective, while $<25 \%$ reduction was ineffective. The criteria of clinical effect (overall effectiveness) were based mainly on reduction in HAMD score after 8 weeks of treatment, and also on HAMD scores less than 8 using the formula below [7].

$O E(\%)=\{(\mathrm{Nr}+\mathrm{Nee}+\mathrm{Ne}) / T\} 100$ (1),

where $O E$ is overall effectiveness, $\mathrm{Nr}$ is number of recovery cases, Nee is number of evidently effective cases, $\mathrm{Ne}$ is number of effective cases, and $T$ is total number of patients (cases).

\section{Evaluation of adverse reactions}

ECG, CBC, biochemical examination, and body weight of all patients were determined before treatment, and at weeks 2, 4, 6, and 8 after treatment during which TESS was used to assess adverse reactions.

\section{Statistical analysis}

Quantitative data are expressed as mean \pm SEM, and $t$-test was used to compare means of two 
samples. Enumeration data were analyzed using chi square $\left(x^{2}\right)$ test. All statistical analyses were carried out with SPSS 18.0.Statistical significance of differences was assumed at $p<$ 0.05 .

\section{RESULTS}

\section{Clinical effectiveness of treatments}

After four treatment courses, there were 30 cured cases, 25 evidently effective cases, 20 effective cases and 4 ineffective cases in the mirtazapine group, with a total effectiveness of $95 \%$. In the fluoxetine group, there were 25 healed cases, 18 evidently effective cases, 30 effective cases, and 6 ineffective cases, with a total effectiveness of $92.4 \%$. There were no significant differences in clinical effectiveness between the two groups ( $p$ $>0.05$ ), but mirtazapine had slight advantage over fluoxetine (Table 1).

\section{HAMD scores}

The HAMD scores in both groups before treatment were comparable $(p>0.05)$. The onset of mirtazapine effectiveness took 2 weeks, while that of fluoxetine took 4 weeks. There was a significant difference in reduction of HAMD score between the two groups after 2 and 4 weeks of treatment $(p<0.05)$. However, the difference was not statistically significant after 6 and 8 weeks of treatment $(p>0.05)$. In addition, there was no difference in reduction of HAMD score between pretreatment and after 8-week posttreatment values $(p<0.05$; Table 2$)$.

\section{Incidence of adverse reactions}

Table 3 shows adverse reactions in the two groups. There were 20 patients $(25.3 \%)$ with slight adverse reactions in mirtazapine group, and 34 patients $(43.0 \%)$ with similar reactions in the fluoxetine group. Most of the adverse reactions occurred in the first treatment course and then disappeared spontaneously with continued treatment. The adverse reactions in the mirtazapine group were sleepiness and dyspepsia, while in the fluoxetine group, insomnia, nausea, vomiting, excitation, and headache were seen. There was significant difference in adverse reaction incidents between the two groups.

Table 1: Effectiveness after 4 treatment courses $\{\mathrm{n}(\%)\}$

\begin{tabular}{lccccc}
\hline Group & Healed & $\begin{array}{c}\text { Evidently } \\
\text { effective }\end{array}$ & Effective & Ineffective & Total effectiveness (\%) \\
\hline Mirtazapine & $30(37.9)$ & $25(31.6)$ & $20(25.3)$ & $4(5.1)$ & 94.9 \\
Fluoxetine & $25(31.6)$ & $18(22.8)$ & $30(37.9)$ & $6(7.7)$ & 92.4 \\
\hline
\end{tabular}

Table 2: HAMD scores pre- and post-treatment (mean \pm SEM, $n=79$ )

\begin{tabular}{lccccc}
\hline Group & $\begin{array}{c}\text { Pre- } \\
\text { treatment }\end{array}$ & $\begin{array}{c}\text { 2 wks post- } \\
\text { treatment }\end{array}$ & $\begin{array}{c}\text { 4 wks post- } \\
\text { treatment }\end{array}$ & $\begin{array}{c}\text { 6 wks post- } \\
\text { treatment }\end{array}$ & $\begin{array}{c}\text { 8 wks post- } \\
\text { treatment }^{* *}\end{array}$ \\
\hline Mirtazapine & $23.4 \pm 1.9$ & $18.4 \pm 1.4$ & $14.4 \pm 2.7$ & $8.7 \pm 1.9$ & $7.5 \pm 2.2^{*}$ \\
Fluoxetine & $23.1 \pm 2.0$ & $21.3 \pm 1.7$ & $19.0 \pm 1.4$ & $9.9 \pm 1.7$ & $8.3 \pm 2.3^{*}$ \\
$t$ & 0.41 & 2.91 & 3.15 & 0.87 & 0.69 \\
$p$ & $>0.05$ & $<0.05$ & $<0.05$ & $>0.05$ & $>0.05$ \\
\hline${ }^{*} P<0.05$, compared with pretreatment; ${ }^{* *}$ wks $=$ weeks & \multicolumn{3}{c}{}
\end{tabular}

Table 3: Incidence of adverse reactions $\{n(\%)\}$

\begin{tabular}{lcccc}
\hline $\begin{array}{l}\text { Adverse } \\
\text { reaction }\end{array}$ & $\begin{array}{c}\text { Mirtazapine } \\
\text { group }(\mathbf{n}=79)\end{array}$ & $\begin{array}{c}\text { Fluoxetine } \\
\text { group }(\mathbf{n}=79)\end{array}$ & $\mathbf{X}^{2}$ & $\boldsymbol{P}$-value \\
\hline Weight gain & $9(11.4)$ & $7(8.9)$ & 0.23 & $>0.05$ \\
Nausea and vomiting & $4(5.1)$ & $8(10.1)$ & 4.56 & $<0.05$ \\
Weakness & $4(5.1)$ & $4(5.1)$ & 0.79 & $>0.05$ \\
Thirst & $5(6.3)$ & $6(7.6)$ & 1.35 & $>0.05$ \\
Excitement & $4(5.1)$ & $8(10.1)$ & 5.43 & $<0.05$ \\
Insomnia & $2(2.5)$ & $9(11.4)$ & 6.12 & $<0.05$ \\
Headache & $1(1.3)$ & $7(8.9)$ & 7.34 & $<0.05$ \\
Sleepiness & $8(10.1)$ & $3(3.8)$ & 5.31 & $<0.05$ \\
Constipation & $33.8)$ & $4(5.1)$ & 0.34 & $>0.05$ \\
Dyspepsia & $10(12.6)$ & $3(3.8)$ & 7.41 & $<0.05$ \\
\hline
\end{tabular}




\section{DISCUSSION}

Mirtazapine is a new multi-target antidepressant with a unique mechanism of action. It promotes norepinephrine (NE) release through blocking a2 receptor, and then enhances nerve conduction. Elevated NE level may heighten the absorption and utilization of 5-HT, thereby relieving symptoms of depression. Studies have shown that mirtazapine exerts good and short-term effects in the treatment of moderate/severe depression, and it is safe, with low side effects and few adverse reactions $[8,9]$.

Fluoxetine, a representative drug of the selective serotonin (5-HT) re-uptake inhibitors (SSRIs), increases 5-HT through reduction of its absorption or blockage of $5-\mathrm{HT}_{2 \mathrm{C}}$ receptor in GABA neurons, thereby enabling the noradrenergic neurons get rid of suppressive excitation and relieve depression $[10,11]$.

The present study was aimed at comparing the clinical effects and adverse reactions associated with the use of mirtazapine and fluoxetine for treating adult depressive patients, because low levels of $5-\mathrm{HT}, \mathrm{NE}$, and dopamine (DA) are the major factors in depression. The results showed that 8 weeks post-treatment, total effectiveness in the mirtazapine group was only slightly superior to that of the fluoxetine group, and HAMD scores of both groups were markedly reduced below pre-treatment values, indicating that both drugs have comparable clinical effects on adult depression. The HAMD score of the mirtazapine group started decreasing 2 weeks from the onset of treatment, while the decreases in HAMD scores in the fluoxetine group decreased from the $4^{\text {th }}$ week. This implies that mirtazapine works faster than fluoxetine, which is consistent with literature $[12,13]$.

Mirtazapine provoked mild adverse reactions which usually occur in the first treatment course, and then disappeared with continuous treatment. Sleepiness and dyspepsia are usually associated with mirtazapine, while fluoxetine usually causes insomnia, nausea, vomiting, excitation, and headache. Indeed, mirtazapine has equal effectiveness with fluoxetine in the treatment of depression but it works faster and has low incidence of adverse reactions. Thus, it is a fast, safe and effective antidepressant which should be widely used in the clinics for treating adult depression.

\section{Limitations of the study}

Only 58 cases were included in this research and the baseline date were not collected and compared in this research which may cause the basis of the research result.

\section{CONCLUSION}

Mirtazapine has similar effect as fluoxetine in the treatment of adult depression, but works faster, with low incidence of adverse reactions. Thus, it is a safer and quicker antidepressant in clinical applications.

\section{DECLARATIONS}

\section{Conflict of Interest}

No conflict of interest associated with this work.

\section{Contribution of Authors}

The authors hereby make a declaration to the effect that this study was carried out by those indicated under the manuscript title, and that they shall be liable for all claims pertaining to the manuscript contents. All the authors read and gave approval for publication of the manuscript for publication. Lijuan $\mathrm{Xu}$ conceived and designed the study; Liping Zhang, Mei Long, Lijuan Xu collected and analysed the data, while Liping Zhang wrote the manuscript.

\section{REFERENCES}

1. Yi HH. Comparison on safety and efficacy of mirtazapine and fluoxetine in treating depression. Contemp Med 2015; 07(21): 131-132.

2. Kleiboer A, Smit J, Bosmans J, Ruwaard J, Andersson G, Topooco N, Berger T, Krieger T, Botella $C$, Baños $R$, et al. European COMPARative Effectiveness research on blended Depression treatment versus treatment-asusual (E-COMPARED): study protocol for a randomized controlled, non-inferiority trial in eight European countries. Trials 2016; 17(1): 387.

3. Liu $P$, Zheng HR, Li LJ, Liu JB, Zhang Y, Liu XY. A analysis of $1 \mathrm{H}$ - MRS of Patients with Treatmentresistant Depression After Transcranial Magnetic Stimulation Treatment. J Hunan Normal Univ (Med Sci) 2015; 12(1): 55-57.

4. Murray CJ, Lopez AD. Alternative projections of mortality and disability by cause 1990-2020: Global Burden of Disease Study. Lancet 1997; 349(9064): 1498-1504.

5. Yu XL. Comparative study on mirtazapine and fluxetine in the treatment of depression. Chin J Pract Nerv Dis 2012; 7(14): 15-16.

6. World Health Organization. Declaration of Helsinki. $\mathrm{Br}$ Med J 1996; 313(7070): 1448-1449.

7. de Boer $T$. The effects of mirtazapine on central noradrenergic and serotonergic neurotransmission. Int Clin Psychopharmacol 1995; 10(4): 19-23. 
8. Benkert O, Szegedi A, Kohnen R. Mirtazapine compared with paroxetine in major depression. $J$ Clin Psychiatry 2000; 61(9): 656-663.

9. Song HR, Bahk WM, Woo YS, Jeong JH, Kwon YJ, Seo JS, Kim W, Kim MD, Shin YC, Lee SY, et al. Efficacy and Tolerability of Generic Mirtazapine (Mirtax) for Major Depressive Disorder: Multicenter, Open-label, Uncontrolled, Prospective Study. Clin Psychopharmacol Neurosci 2015; 13(2): 144-149.

10. Deng H, He YH, Cheng WR, Yang Y. Study on efficacy and safety of combining olanzapine and fluoxetine in treating depression. J Int Psychl 2015; 2(13): 18-20.

11. Detke HC, Delbello MP, Landry J, Usher RW. Olanzapine/Fluoxetine combination in children and adolescents with bipolar I depression: a randomized, double-blind, placebo-controlled trial. J Am Acad Child Adolesc Psychiatry 2015; 54(3): 217-224.

12. Watanabe N, Omori IM, Nakagawa A, Barbui C, McGuire $H$, Churchill R, Furukawa TA. Mirtazapine versus other antidepressants in the acute-phase treatment of adults with major depression: systematic review and metaanalysis. J Clin Psychiatry 2008; 69(9): 1404-1415.

13. Enck P, Leinert J, Smid M, Köhler T, Schwille-Kiuntke J. Functional Constipation and Constipation-Predominant Irritable Bowel Syndrome in the General Population: Data from the GECCO Study. Gastroenterol Res Pract 2016; 2016(9): 3186016. 